\title{
Improvement of plant growth and nickel uptake by nickel resistant-plant-growth promoting bacteria
}

\author{
Ying Ma*, Mani Rajkumar, Helena Freitas \\ Centre for Functional Ecology, Department of Botany, University of Coimbra, Coimbra 3000, Portugal
}

\section{A R T I C L E I N F O}

\section{Article history:}

Received 14 July 2008

Received in revised form

10 November 2008

Accepted 2 December 2008

Available online $\mathrm{xxx}$

\section{Keywords:}

PGPB

Nickel

Siderophores

IAA

Phytoremediation

\begin{abstract}
A B S T R A C T
In this study, among a collection of Ni-resistant bacterial strains isolated from the rhizosphere of Alyssum serpyllifolium and Phleum phleoides grown on serpentine soil, five plant growth-promoting bacteria (PGPB) were selected based on their ability to utilize 1-aminocyclopropane-1-carboxylate (ACC) as the sole N source and promote seedling growth. All of the strains tested positive for indole-3-acetic acid (IAA) production and phosphate solubilization. In addition, four of the strains exhibited significant levels of siderophores production. Further, the efficiency of PGPB in enhancing Ni solubilization in soils was analyzed. Compared with control treatment, inoculation of PGPB strains significantly increased the concentrations of bioavailable Ni. Furthermore, a pot experiment was conducted to elucidate the effects of inoculating Ni-resistant PGPB on the plant growth and the uptake of Ni by Brassica juncea and B. oxyrrhina in soil contaminated with $450 \mathrm{mg} \mathrm{kg}^{-1} \mathrm{Ni}$. Psychrobacter sp. SRA2 significantly increased the fresh (351\%) and dry biomass ( $285 \%)$ of the B. juncea test plants $(p<0.05)$, whereas Psychrobacter sp. SRA1 and Bacillus cereus SRA10 significantly increased the accumulation of $\mathrm{Ni}$ in the root and shoot tissues of $B$. juncea compared with non-inoculated controls. This result indicates that the strains SRA1 and SRA10 facilitated the release of $\mathrm{Ni}$ from the non-soluble phases in the soil, thus enhancing the availability of Ni to plants. A significant increase, greater than that of the control, was also noted for growth parameters of the $B$. oxyrrhina test plants when the seeds were treated with strain SRA2. This effect can be attributed to the utilization of ACC, solubilization of phosphate and production of IAA. The results of the study revealed that the inoculation of Ni mobilizing strains Psychrobacter sp. SRA1 and B. cereus SRA10 increases the efficiency of phytoextraction directly by enhancing the metal accumulation in plant tissues and the efficient PGPB, Psychrobacter sp. SRA2 increases indirectly by promoting the growth of B. juncea and B. oxyrrhina.
\end{abstract}

(C) 2008 Elsevier B.V. All rights reserved.

\section{Introduction}

Heavy metal pollution of soils is becoming one of the most severe environmental hazards and has negative impact on human health and agriculture. Elevated levels of heavy metals not only decrease soil microbial activity, soil fertility and yield losses [1], but also threaten human health through the food chain [2]. Phytoextraction is emerging as a potential cost effective solution for the remediation of heavy metal-contaminated soils in opposition to the conventional chemical and physical remediation technologies that are generally too costly and often harmful to soil characteristics $[3,4]$. Some plant species (identified as hyperaccumulators) growing in heavy metal-contaminated sites have been found with the ability to accumulate unusually high concentrations of heavy metals without impacting on their growth and development [5]. However, most hyperaccumulators identified so far are not suitable for field phy-

\footnotetext{
* Corresponding author. Tel.: +351 239 855243; fax: +351 239855211.

E-mail address: cathymaying@yahoo.com.cn (Y. Ma).
}

toremediation applications due to their small biomass and slow growth [6]. Moreover, the metals at elevated levels are generally toxic to most plants impairing their metabolism and reducing plant growth. These properties have an adverse impact on the potential for metal phytoextraction and restrict the employment of this technology. Thus, the development of phytoremediation strategies for heavy metal-contaminated soils is necessary. In this regard, interactions among metals, rhizosphere microbes and plants have attracted attention because of the biotechnological potential of microorganisms for metal removal directly from polluted soils or the possible transfer of accumulated metals to higher plants [7]. Further, the rhizosphere provides a complex and dynamic microenvironment where microorganisms, in association with roots, form unique communities that have considerable potential for plant growth promotion [8] and detoxification of hazardous waste compounds $[9,10]$. In addition, certain metal resistant microorganisms can affect on trace metal mobility and availability to the plants through release of chelating agents, acidification, phosphate solubilization and redox changes [11,12]. Therefore, improvement of the interactions between plants and beneficial rhizosphere microbes 
can enhance biomass production and tolerance of the plants to heavy metals. Further, the microorganisms isolated from natural environments contaminated with heavy metals often exhibit tolerance to multiple pollutants as they have adapted to such environments. Thus, isolation of metal resistant strains from an appropriate metal-contaminated soils could be of importance for a given phytoremediation strategy.

Currently, the serpentine areas are considered as an interesting model for the evolution of metal resistant-plant growth promoting microorganisms, completely different from that of artificially contaminated soils. Bacterial communities in serpentine soil were reported to tolerate spiking of metals, such as nickel, lead, copper and zinc [11,13,14]. Also, evidence was presented that the rhizosphere of hyperaccumulating plants, such as Sebertia acuminata, Thlaspi goesingense, Alyssum murale and A. bertolonii has an increased proportion of metal resistant bacteria $[11,12,15,16]$. Furthermore, the root associated bacteria isolated from serpentine environment have been reported to be able to produce plant growth promoting substances such as indole-3-acetic acid (IAA), siderophores and 1-aminocyclopropane-1-carboxylate (ACC) deaminase [12,17]. Therefore, inoculation of such rhizosphere organisms endowed with metal tolerating ability and plant growth-promoting activities are of practical importance for both the metal-contaminated environment and for the plant growth promotion.

Our aim was to isolate and characterize Ni-resistant bacteria associated with the rhizosphere of Alyssum serpyllifolium and Phleum phleoides grown in serpentine soils, and to select plant growth-promoting bacteria (PGPB) which might be useful to increase the plant growth and $\mathrm{Ni}$ uptake by Brassica species ( $B$. juncea and $B$. oxyrrhina) in soil. The creation of such metal tolerant plant-serpentine microbe associations is aimed at improving the efficiency of phytoremediation of heavy metal polluted soils.

\section{Methods}

\subsection{Isolation of Ni-resistant PGPB}

The bacterial strains were isolated from the rhizosphere of A. serpyllifolium and $P$. phleoides grown in serpentine soils in Bragança, north-east of Portugal, previously described by Freitas et al. [18]. About $1 \mathrm{~g}$ of soil samples were serially diluted using $25 \mathrm{mM}$ phosphate buffer and spread over on Luria-Bartani medium (LB) amended with $50 \mathrm{mg}$ of $\mathrm{Nil}^{-1}\left(\mathrm{NiCl}_{2}\right)$. The plates were incubated at $37^{\circ} \mathrm{C}$ for $48 \mathrm{~h}$. From the Ni-resistant colonies, different strains were picked and purified on the LB medium containing $50 \mathrm{mg} \mathrm{l}^{-1}$ of Ni according to the procedure of Rajkumar et al. [19]. Purified colonies were gradually taken to higher concentration of $\mathrm{Ni}$ (50-1500 $\mathrm{mg} \mathrm{l}^{-1}$ ) and the same procedure was continued to isolate Ni-resistant strains.

In order to isolate the PGPB, the heavy metal resistant strains were grown on DF salts minimal medium [20] supplemented with $3 \mathrm{mM}$ ACC to provide a nitrogen source at $27^{\circ} \mathrm{C}$ for $120 \mathrm{~h}$ at $175 \mathrm{rpm}$. The inoculated DF salt minimal medium without ACC was used as a blank. The bacterial growth was monitored as a function of biomass by measuring the optical density at $600 \mathrm{~nm}$ against blank. Further, the ACC utilizing strains were assessed for the plant growth promoting activity by roll towel method [21]. Seeds of B. juncea and B. oxyrrhina were surface sterilized in $2 \%$ $\mathrm{Ca}(\mathrm{OCl})_{2}(2 \mathrm{~h})$ and rinsed several times with sterile distilled water. The seeds were inoculated by soaking in a bacterial suspension after adjusting $\mathrm{OD}_{600 \mathrm{~nm}}$ to 1 for $2 \mathrm{~h}$ then placed in wet blotters and incubated in a growth chamber for 20 days. The germination percentage of seeds was recorded and the vigour index was calculated using the formula described by Abdul-Baki and Anderson [22].

\subsection{Genetic characterization of Ni-resistant PGPB}

The bacterial strains were grown in LB broth in presence of $58 \mathrm{mg} \mathrm{Nil} \mathrm{m}^{-1}$ at $30^{\circ} \mathrm{C}$. Cells were harvested after $20 \mathrm{~h}$ and processed immediately for DNA extraction using standard procedure [23]. Amplification of $16 \mathrm{~S}$ rRNA gene sequence was performed by PCR with the conserved eubacterial primers $\mathrm{PA}$ ( $5^{\prime}$ AGAGTTTGATCCTGGCTCAG; Escherichia coli bases 8-27) and pC5B (5'-TACCTTGTTACGACTT; E. coli bases 1507-1492) [24]. Reaction conditions were as described by Branco et al. [25]. Each amplification mixture $(5 \mu \mathrm{l})$ was analyzed by agarose gel $(1.5 \%, \mathrm{w} / \mathrm{v})$ electrophoresis in TAE buffer (0.04 M Tris acetate, 0.001 M EDTA) containing $1 \mu \mathrm{g} \mathrm{m}^{-1}(\mathrm{w} / \mathrm{v})$ ethidium bromide. For further sequencing reaction, the amplified DNA was purified from salts and primers using the PCR purification kit (Roche Diagnostics) according to the manufacturer's instructions. Automated sequencing of the purified PCR products was performed using the dRodamina terminator cycle sequencing kit and the ABI 310 DNA Sequencer (Applied Biosystems, Foster City, CA) according to the manufacturer's instructions. Partial 16S rDNA sequences obtained were matched against nucleotide sequences present in GenBank using the BLASTn program [26].

\subsection{Influence of PGPB and Ni on the growth of Brassica species and Ni uptake}

For pot experiments the soil was collected from the Botanical Garden, Department of Botany, University of Coimbra, Coimbra, Portugal. The soil was sieved $(2 \mathrm{~mm})$ and sterilized by steaming $\left(10^{\circ} \mathrm{C}\right.$ for $1 \mathrm{~h}$ on three consecutive days). After sterilization the soil was amended with aqueous solution of $\mathrm{NiCl}_{2}$ to achieve the final $\mathrm{Ni}$ concentrations of $450 \mathrm{mg} \mathrm{kg}^{-1}$ and left in a greenhouse for a 2 weeks period (for metal stabilization). The surface sterilized seeds of $B$. juncea and $B$. oxyrrhina were inoculated with PGPB as detailed in earlier section. Seeds soaked in sterile water were used as control. The inoculated and non-inoculated seeds were planted in plastic pot (top diameter $120 \mathrm{~mm}$, bottom $100 \mathrm{~mm}$ and height $90 \mathrm{~mm}$ ) containing $300 \mathrm{~g}$ of soil. The plants were grown in a glasshouse at $25^{\circ} \mathrm{C}$ and a $16 / 8$ day/night regime. After 45 days the plants were carefully removed from the pots and the root surface was cleaned several times with distilled water. Growth parameters such as fresh weight and dry weight of the plants were measured. The accumulation of $\mathrm{Ni}$ in root and shoot system was also quantified following the method of Freitas et al. [18].

\subsection{Characterization of plant growth-promoting features of PGPB}

\subsubsection{ACC deaminase activity}

The ACC deaminase activity of cell-free extracts was determined by estimating the amount of $\alpha$-ketobutylate $(\alpha-\mathrm{KB})$ generated by the enzymatic hydrolysis of ACC [8] by comparing the absorbance at $540 \mathrm{~nm}$ of a sample to a standard curve of $\alpha$-ketobutylate ranging between 0.1 and $1.0 \mathrm{mmol}$ according to the procedure of Honma and Shimomura [27].

\subsubsection{Production of IAA}

IAA production by PGPB was determined according to the method of Bric et al. [28]. Briefly, an aliquot of $2 \mathrm{ml}$ supernatant obtained from bacterial culture grown in LB medium with L-tryptophan $\left(500 \mu \mathrm{g} \mathrm{ml}^{-1}\right)$ was mixed with $100 \mu \mathrm{l}$ of $10 \mathrm{mM}$ orthophosphoric acid and $4 \mathrm{ml}$ of reagent $\left(1 \mathrm{ml}\right.$ of $0.5 \mathrm{M} \mathrm{FeCl}_{3}$ in $50 \mathrm{ml}$ of $35 \% \mathrm{HClO}_{4}$ ). The absorbance of pink color developed after $25 \mathrm{~min}$ incubation was read at $530 \mathrm{~nm}$. The IAA concentration in culture was determined using a calibration curve of pure IAA as a standard following the linear regression analysis. 


\subsubsection{Production of siderophores}

PGPB were screened for the production of siderophores by the method of Schwyn and Neilands [29] using chrome azurol S (CAS) agar. Briefly, the assay was performed by spotting $50 \mu \mathrm{l}$ of each exponential bacterial culture previously grown under ironrestricted conditions in casamino acids (CAA) medium onto CAS agar. The siderophore levels produced by the strains were recorded as the diameter of the orange halo produced by the colony. The presence of catechol and hydroxamate siderophores in culture supernatants obtained from bacteria grown either in iron-restricted conditions in CAA medium was quantitatively determined by the calorimetric assay of Arnow [30], using 2,3-dihydroxybenzoic acid and the Atkin et al. [31] method, using desferrioxamine mesylate as standards, respectively.

\subsubsection{Solubilization of phosphate}

The phosphate solubilizing activity of the strains was analyzed in modified Pikovskayas medium [32] amended with 0.5\% of tricalcium phosphate. The strains were grown at $27^{\circ} \mathrm{C}$ for $120 \mathrm{~h}$ at $200 \mathrm{rpm}$. The solubilized phosphate in the culture supernatant was quantified as detailed by Fiske and Subbarow [33].

\subsubsection{Effects of PGPB on the mobility of soil metals}

Batch studies on the effects of bacteria on the mobility of soil metals were carried out by using $50-\mathrm{ml}$ scaled polypropylene centrifuge tubes. The sterilized soil was artificially contaminated with $\mathrm{Ni}$ as detailed in earlier section. Pure culture bacterial strains were grown in LB broth and placed on a shaker at $200 \mathrm{rpm}$ and $27^{\circ} \mathrm{C}$. After $24 \mathrm{~h}$, optical density $(600 \mathrm{~nm})$ was measured and adjusted to 1.5; the cultures were centrifuged at $6000 \mathrm{rpm}$ for 10 min, washed in phosphate buffer ( $\mathrm{pH} \mathrm{7.0)}$ twice, resuspended, washed in sterile water, recentrifuged, and finally resuspended in $5 \mathrm{ml}$ sterile water. Small aliquots of washed bacterial culture (up to $1 \mathrm{ml}$ ) were added to the $1 \mathrm{~g}$ of soil in the centrifuge tubes. Sterile water was added to soil as an axenic control. All tubes were weighed, wrapped in brown paper and placed on an orbital shaker at $200 \mathrm{rpm}$ at $27^{\circ} \mathrm{C}$. After 5 days, the tubes were again weighed to compensate for evaporation of water. Ten milliliters of sterile water were added to each tube to extract the soil water soluble Ni [34]. The soil suspensions were centrifuged at $7000 \mathrm{rpm}$ for $10 \mathrm{~min}$ and filtered. The concentrations of $\mathrm{Ni}$ in the filtrate were determined by atomic absorption spectrophotometer.

\subsection{Statistical analysis}

Analysis of variance (ANOVA) followed by post hoc Fisher LSD test $(p<0.05)$ were used to compare treatment means. All the statistical analysis were carried out using SPSS 10.0.

\section{Results and discussion}

\subsection{Isolation and characterization of Ni-resistant PGPB}

Even metals exert their toxic effects on microorganisms through various mechanisms, the metal-tolerant bacteria could survive in these habitats and could be isolated and selected for their potential application in the bioremediation of contaminated sites [35]. Especially, bacteria present in serpentine soil and their interaction with hyperaccumulating plants have attracted the attention of several investigators [16,34-37] due to biotechnological applications for bioremediation. In this investigation, the bacterial strains were isolated from the rhizosphere of $A$. serpyllifolium and $P$. phleoides with an objective to assess the effects of PGPB on the growth and $\mathrm{Ni}$ accumulation potential of B. juncea and B. oxyrrhina in Ni contaminated soil. During the initial screening, 30 colonies were screened from initial $\left(50 \mathrm{mgl}^{-1}\right)$ level of Ni supplemented LB medium. In order to isolate the PGPB, the Ni-resistant strains were tested for the ability to grow on DF salts minimal medium with ACC. Among the 30 strains tested, 5 strains namely SRA1, SRA2, SRA10, SRP4 and SRP12 grew in DF salts minimal medium with ACC as the sole source of nitrogen (data not shown). Bacterial strains utilizing ACC as a sole source of nitrogen possess ACC deaminase which hydrolyzes ACC and enhance the elongation of plant roots [38]. Earlier studies have confirmed the potential of ACC utilizing bacteria to promote the root elongation and growth of Brassica campestris, $B$. napus, B. juncea, Arabidopsis thaliana, Lycopersicon esculentum, Zea Mays and Triticum aestivum plants [39-45]. Hence, the ACC utilizing strains were further assessed for plant growth promoting activity by roll towel method. In general, the inoculation of ACC utilizing strains showed an increase in the vigour index of $B$. juncea and $B$. oxyrrhina (Table 1 ). However, strain SRA1 showed a maximum increase in root length, shoot length and vigour index of both plant species compared with respective non-inoculated plants. For instance, inoculation of $B$. juncea with strain SRA1 increased the root length, shoot length and vigour index by $82 \%$, 96\% and $123 \%$, respectively. Previously, copper-resistant Achromobacter xylosoxidans isolated from soil contaminated with copper and other heavy metals has been shown to promote plant growth [45]. Jiang et al. [44] also investigated that a heavy metal resistant Burkholderia sp. J62 isolated from heavy metal-contaminated soils prompted plant growth by the synthesis of ACC deaminase. Similarly, Rajkumar and Freitas [46] isolated Ni-resistant Pseudomonas sp. Ps29C and Bacillus megaterium $\mathrm{Bm} 4 \mathrm{C}$ from serpentine soil for promoting $B$. juncea growth in $\mathrm{Ni}$ contaminated soils.

The ACC utilizing strains exhibited a high tolerance to $\mathrm{Ni}$ when cultivated under increasing $\mathrm{Ni}$ levels in the growth medium. Extremely high $\mathrm{Ni}$ resistance (up to the concentration of $1250 \mathrm{mg} \mathrm{l}^{-1}$ ) was observed for the strains SRA10 and SRP12, whereas strains SRA1 and SRP4 showed relatively low tolerance to $\mathrm{Ni}\left(500 \mathrm{mg} \mathrm{l}^{-1}\right.$ ). The remaining strain SRA2 tolerated up to the

Table 1

Influence of PGPB on root length, shoot length and vigour index of B. juncea and B. oxyrrhina.

\begin{tabular}{|c|c|c|c|c|c|c|}
\hline \multirow[t]{2}{*}{ PGPB strains } & \multicolumn{3}{|l|}{ B. juncea } & \multicolumn{3}{|l|}{ B. oxyrrhina } \\
\hline & Root length (cm) & Shoot length $(\mathrm{cm})$ & Vigour index ${ }^{\mathrm{a}}$ & Root length (cm) & Shoot length $(\mathrm{cm})$ & Vigour index* \\
\hline Control & $8.51 \pm 0.39 c$ & $2.80 \pm 0.08 \mathrm{~d}$ & $848 \mathrm{e}$ & $10.10 \pm 0.07 d$ & $2.03 \pm 0.14 b$ & $1092 c$ \\
\hline Psychrobacter sp. SRA1 & $15.50 \pm 0.34 a$ & $5.50 \pm 0.09 a$ & $1890 a$ & $12.41 \pm 0.01 a$ & $3.28 \pm 0.18 a$ & $1413 a$ \\
\hline Psychrobacter sp. SRA2 & $12.80 \pm 0.61 b$ & $4.80 \pm 0.05 b$ & $1408 c$ & $11.17 \pm 0.50 c$ & $2.83 \pm 0.41 b$ & $1330 \mathrm{~b}$ \\
\hline Bacillus cereus SRA10 & $14.70 \pm 0.26 a$ & $4.20 \pm 0.05 c$ & $1418 c$ & $11.74 \pm 0.09 b$ & $3.25 \pm 0.52 \mathrm{a}$ & 1349a \\
\hline Bacillus sp. SRP4 & $13.10 \pm 0.86 b$ & $4.97 \pm 0.12 b$ & $1536 b$ & $10.38 \pm 0.14 d$ & $2.43 \pm \pm 0.28 b$ & $1153 c$ \\
\hline Bacillus weihenstephanensis SRP12 & $9.50 \pm 0.28 c$ & $4.00 \pm 0.49 c$ & $1080 d$ & $10.24 \pm 0.06 \mathrm{~d}$ & $2.29 \pm 0.23 b$ & $1128 \mathrm{c}$ \\
\hline
\end{tabular}

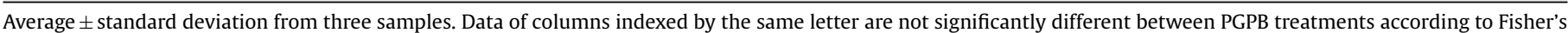
protected LSD test $(p<0.05)$.

a Vigour index = germination $(\%) \times$ seedling length $($ shoot length + root length $)$ 
Table 2

Influence of PGPB and Ni on fresh weight and dry weight of Brassica species.

\begin{tabular}{|c|c|c|c|c|}
\hline \multirow[t]{2}{*}{ PGPB strains } & \multicolumn{2}{|l|}{ B. juncea } & \multicolumn{2}{|l|}{ B. oxyrrhina } \\
\hline & Fresh weight (mg plant ${ }^{-1}$ ) & Dry weight (mg plant ${ }^{-1}$ ) & Fresh weight (mg plant ${ }^{-1}$ ) & Dry weight (mg plant ${ }^{-1}$ ) \\
\hline Control & $339.3 \pm 6.4^{\mathrm{d}}$ & $25.3 \pm 2.0^{c}$ & $279.3 \pm 15.0^{\mathrm{a}}$ & $10.9 \pm 0.4^{\mathrm{a}}$ \\
\hline $\mathrm{Ni}$ & $232.3 \pm 10.1^{\mathrm{e}}$ & $12.3 \pm 1.5^{\mathrm{e}}$ & $126.0 \pm 7.5^{c}$ & $6.0 \pm 0.2^{\mathrm{d}}$ \\
\hline $\mathrm{Ni}+$ Psychrobacter sp. SRA1 & $215.0 \pm 5.3^{e}$ & $15.0 \pm 0.8^{\mathrm{d}}$ & $128.0 \pm 9.5^{c}$ & $7.0 \pm 0.3^{c}$ \\
\hline $\mathrm{Ni}+$ Psychrobacter sp. SRA2 & $1047.3 \pm 20.6^{a}$ & $47.3 \pm 1.2^{\mathrm{a}}$ & $158.0 \pm 6.6^{b}$ & $8.1 \pm 0.5^{\mathrm{bc}}$ \\
\hline $\mathrm{Ni}+$ Bacillus cereus SRA10 & $330.3 \pm 15.9^{d}$ & $17.3 \pm 1.5^{\mathrm{d}}$ & $151.3 \pm 8.0^{\mathrm{bc}}$ & $7.9 \pm 0.6^{c}$ \\
\hline $\mathrm{Ni}+$ Bacillus sp. SRP4 & $699.0 \pm 18.4^{\mathrm{b}}$ & $32.6 \pm 2.1^{\mathrm{b}}$ & $136.3 \pm 7.0^{\mathrm{bc}}$ & $7.7 \pm 0.5^{c}$ \\
\hline $\mathrm{Ni}+$ Bacillus weihenstephanensis SRP12 & $558.6 \pm 18.0^{c}$ & $26.3 \pm 2.5^{c}$ & $136.3 \pm 5.9^{b c}$ & $7.0 \pm 0.7^{c}$ \\
\hline
\end{tabular}

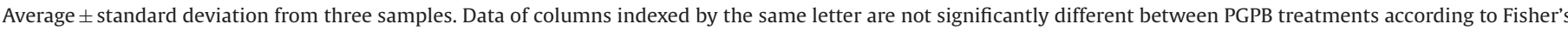
protected LSD test $(p<0.05)$.

Ni concentration of $750 \mathrm{mg} \mathrm{l}^{-1}$. This high tolerance to Ni could be attributed to the fact that the bacteria were isolated from a serpentine soil containing high levels of $\mathrm{Ni}$ [18]. Microorganisms isolated from natural environments contaminated with heavy metals often exhibit tolerance to multiple pollutants as they have adapted to such environments [36]. On the basis of morphological, physiological, biochemical characteristics (data not shown) and comparative analysis of the partial sequence with already available database showed that the strains SRA1 (498 bp) and SRA2 (738bp) were close to the members of the genus Psychrobacter. Strain SRA10 (735 bp) was identified as Bacillus cereus and SRP4 (650 bp) showed high similarity with Bacillus sp., as did SRP12 (499bp) with Bacillus weihenstephanensis. The sequences were deposited at GenBank (Psychrobacter sp. SRA1, accession no. FM180059; Psychrobacter sp. SRA2, accession no. FM180060; B. cereus SRA10, accession no. FM180061; Bacillus sp. SRP4, accession no. FM180062; Bacillus weihenstephanensis SRP12, accession no. FM180063).

\subsection{Influence of PGPB and Ni on plant growth and Ni uptake}

The bacterial inoculated and non-inoculated plants were subjected to the $\mathrm{Ni}$ concentration of $450 \mathrm{mg} \mathrm{kg}^{-1}$ in the soil for 45 days responded differently in terms of plant growth (Table 2 ). $\mathrm{Ni}$ is known to inhibit enzymatic activity [47,48], biosynthesis of chlorophyll and protein [49], and henceforth the overall growth of plants. In our experiment both in B. juncea and B. oxyrrhina, the reduction of plant fresh weight and dry weight were noticed as reported by others $[46,50]$. In Ni-amended soil condition, the value of growth parameters in $B$. juncea plants was decreased considerably (Table 2), with a $32 \%$ reduction in fresh weight and $51 \%$ reduction in dry weight. B. juncea inoculated with PGPB strains SRA2, SRA10, SRP4 and SRP12 exhibited an increase in plant fresh and dry weight in the presence of Ni. However, the highest plant growth promoting effect was found for strain SRA2, which enhances plant fresh and dry weight by $351 \%$ and $285 \%$, respectively, compared with noninoculated plants. Similar responses were also obtained with $B$. oxyrrhina, where reduction of fresh weight and dry weight were observed (55\% and $45 \%$, respectively) under Ni stress condition. However, B. oxyrrhina inoculated with PGPB exhibited an increase in plant fresh and dry weight in the presence of Ni. Similarly, maximum plant growth promoting effect was observed in strain SRA2, which enhances plant fresh and dry weight by $25 \%$ and $35 \%$, respectively. The results obtained here clearly indicate that inoculation with strain SRA2 was highly efficient at protecting B. juncea and $B$. oxyrrhina from growth inhibition caused by toxic soil Ni concentrations. This result is in agreement with a previous report describing increased biomass production of $B$. juncea inoculated with ACC utilizing strains and grown in Ni-supplemented soil [46]. A decreased toxicity of other heavy metals such as $\mathrm{Ni}, \mathrm{Pb}$ and $\mathrm{Zn}$ was also observed in B. juncea and B. campestris plants inoculated with Kluyvera ascorbata SUD165 containing ACC deaminase [51].
Since the process of metal uptake and accumulation by different plants depends on various internal and external factors [52], we assessed whether inoculation with PGPB affected the uptake of Ni by $B$. juncea and $B$. oxyrrhina plants (Fig. 1 ). In general both $B$. juncea and B. oxyrrhina showed similar effects on Ni uptake, although the $B$. oxyrrhina accumulated more $\mathrm{Ni}$ in both shoots and roots than $B$. juncea. Further, the inoculation of PGPB strains SRA1 and SRA10 significantly increased the accumulation of $\mathrm{Ni}$ in the root and shoot tissues of $B$. juncea compared with non-inoculated
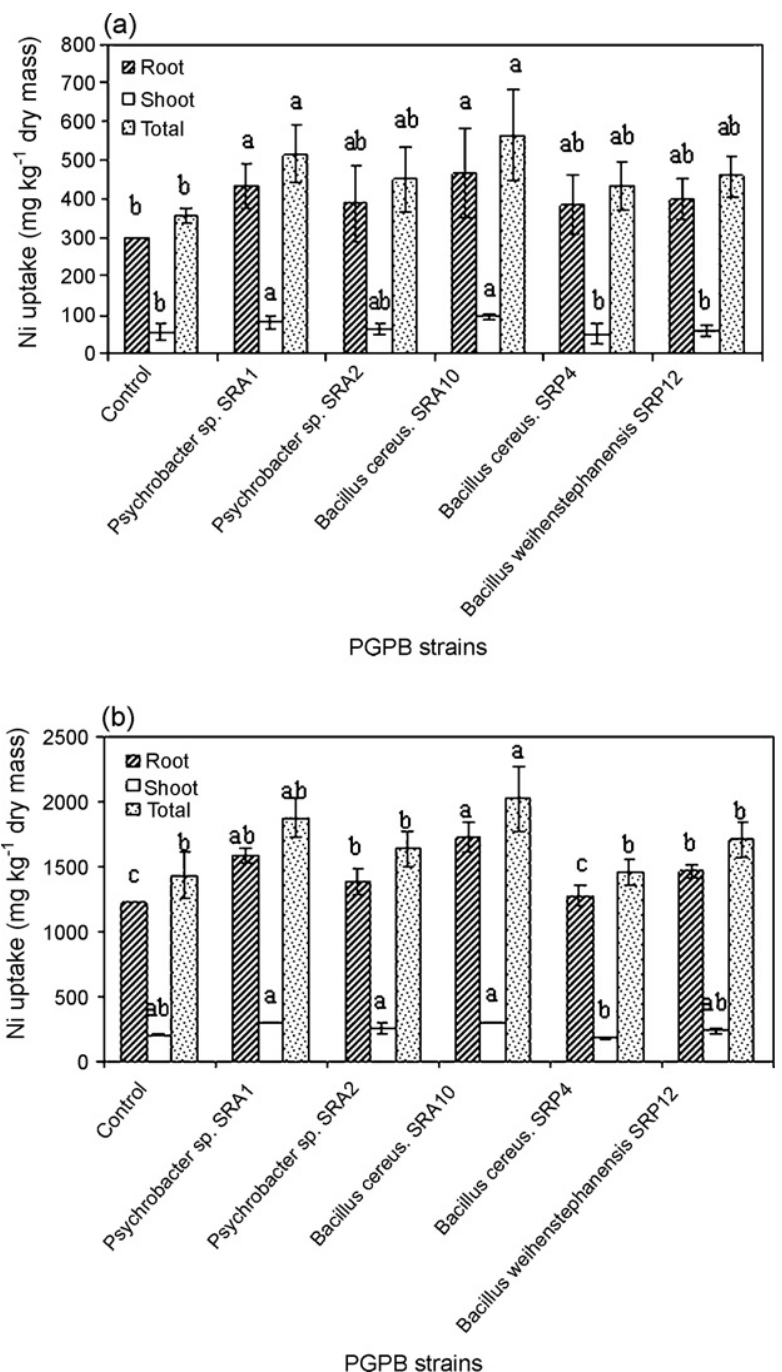

Fig. 1. Ni concentration ( $\left.\mathrm{mg} \mathrm{kg}^{-1}\right)$ in B. juncea (a) and B. oxyrrhina (b). Data of columns indexed by the same letter are not significantly different between PGPB treatments according to Fisher's protected LSD test $(p<0.05)$. 
Table 3

Characteristics of the isolated Ni-resistant PGPB strains.

\begin{tabular}{|c|c|c|c|c|c|c|}
\hline \multirow[t]{2}{*}{ Strain } & \multirow{2}{*}{$\begin{array}{l}\text { ACC deaminase } \\
\left(\mu \mathrm{m} \alpha-\mathrm{KB} \mathrm{mg}^{-1} \mathrm{~h}^{-1}\right)\end{array}$} & \multirow{2}{*}{$\begin{array}{l}\text { Phosphate } \\
\text { solubilization }\left(\mathrm{mg} \mathrm{l}^{-1}\right)\end{array}$} & \multirow[t]{2}{*}{ IAA synthesis $\left(\mathrm{mg} \mathrm{l}^{-1}\right)$} & \multicolumn{3}{|c|}{ Siderophore production } \\
\hline & & & & CAS assay $(\mathrm{cm})$ & Catechol $\left(\mathrm{mg} \mathrm{l}^{-1}\right)$ & $\begin{array}{l}\text { Hydroxamate } \\
\left(\mathrm{mg} \mathrm{l}^{-1}\right)\end{array}$ \\
\hline Psychrobacter sp. SRA1 & $15 \pm 2.08^{\mathrm{d}}$ & $122.48 \pm 1.03^{b}$ & $76.73 \pm 0.43^{b}$ & $2.4 \pm 0.20^{\mathrm{b}}$ & $940 \pm 26.91^{\mathrm{a}}$ & $82 \pm 1.92^{\mathrm{a}}$ \\
\hline Psychrobacter sp. SRA2 & $55 \pm 2.52^{b}$ & $119.25 \pm 1.47^{b}$ & $87.66 \pm 0.39^{a}$ & nd & nd & nd \\
\hline Bacillus cereus SRA10 & $24 \pm 3.00^{c}$ & $145.00 \pm 0.85^{\mathrm{a}}$ & $72.51 \pm 0.40^{d}$ & $2.9 \pm 0.10^{\mathrm{a}}$ & $971 \pm 5.03^{a}$ & $84 \pm 0.36^{a}$ \\
\hline Bacillus sp. SRP4 & $111 \pm 4.04^{\mathrm{a}}$ & $106.74 \pm 7.23^{c}$ & $22.03 \pm 0.48^{e}$ & $2.3 \pm 0.20^{\mathrm{b}}$ & $665 \pm 23.35^{b}$ & $63 \pm 1.67^{b}$ \\
\hline Bacillus weihenstephanensis SRP12 & $60 \pm 2.00^{b}$ & $109.74 \pm 1.47^{c}$ & $74.91 \pm 0.51^{c}$ & $2.3 \pm 0.10^{\mathrm{b}}$ & $350 \pm 32.74^{c}$ & $37 \pm 5.90^{c}$ \\
\hline
\end{tabular}

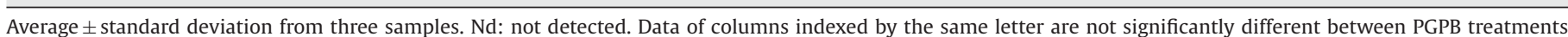
according to Fisher's protected LSD test $(p<0.05)$.

controls (Fig. 1). For instance, strain SRA10 increased the Ni concentration in the root and shoot tissues by $56 \%$ and $73 \%$, respectively. Similarly, the concentration of $\mathrm{Ni}$ in root tissues of $B$. oxyrrhina was increased after inoculation with strains SRA1 and SRA10, but the concentration of $\mathrm{Ni}$ in shoot system of plants inoculated with PGPB was not significantly affected compared with respective control (Fig. 1). This study indicates that PGPB facilitated the release of $\mathrm{Ni}$ from the non-soluble phases in the soil, thus enhancing the availability of $\mathrm{Ni}$ to plants. A possible explanation might be acid reducing soil $\mathrm{pH}$, siderophore production and phosphate solubilization $[44,50,53,54]$. These effects of inoculation were reported also by Rajkumar and Freitas [34], who found that the addition of Pseudomonas jessenii to surface sterilized root of Ricinus communis in autoclaved soil increased $\mathrm{Ni}, \mathrm{Cu}$ and $\mathrm{Zn}$ concentrations in root tissues compared with non-inoculated controls. In contrast to the present observation, Madhaiyan et al. [55] reported that inoculation with PGPB reduced $\mathrm{Ni}$ and $\mathrm{Cd}$ uptake in tomato plants. Previously, $B$. juncea grown in Ni-amended soil was found to be able to accumulate significant amount of nickel in its shoots [56]. However in this work, it was found that the inoculated and non-inoculated root systems accumulated considerably more nickel as compared to shoot systems. This can be attributed to poor translocation of nickel from root to shoot system [57]. The accumulation of Ni was more in the roots than shoots showing less translocation of metals from the under ground part to the aerial part of the plant. The present observations indicate that the PGPB protect the plants against the inhibitory effects of nickel.

Although the tested serpentine strains utilize ACC as sole source of nitrogen, the stimulating effect on plant growth under Ni stress varied greatly among bacterial strains and plant species. It may be due to the efficiency of serpentine strains to utilize ACC as the sole source of nitrogen [58]. Further, previous studies have reported that the metal resistant bacterial strains exert their beneficial effects on plant growth by several mechanisms. The mechanisms include: synthesis of siderophore, which can solubilize and sequester iron from the soil $[13,46,59]$; production of phytohormones, which can enhance the growth of plants $[45,54]$ and solubilization of phosphate $[44,60]$. Hence, the plant growth-promoting characteristics such as the ACC deaminase activity, production of IAA, siderophore, and solubilization of phosphate were further investigated in detail.

\subsection{Plant growth-promoting features of Ni-resistant PGPB}

The ACC deaminase activity of serpentine strains was determined by estimating the amount of $\alpha-K B$ generated by the enzymatic hydrolysis of ACC. Among the five strains, SRP4 recorded the highest ACC deaminase activity followed by SRP12 (Table 3). The role of ACC deaminase in decreasing ethylene levels by the enzymatic hydrolysis of ACC into $\alpha-\mathrm{KB}$ and ammonia has been presented as one of the major mechanisms of PGPB in promoting root $[8,39]$ and plant growth under metal stress condition [61].

The siderophore is another important metabolite released by the plant growth-promoting rhizobacteria that indirectly alleviate heavy metal toxicity by increasing the supply of iron to the plant $[51,57]$. In the present study, production of siderophores by serpentine strains was also determined. Among the five strains tested, SRA1, SRA10, SRP4 and SRP12 displayed a positive siderophore activity, as indicated by the development of orange-colored zone on CAS agar plates, after 5 days of growth. Furthermore, maximum production of catachol siderophore was recorded in the strains SRA1, SRA10 and SRP4 (Table 3). Besides, the strain SRA10 recorded the maximum production of hydroxamate siderophores followed by SRA1. It is assumed that the siderophores released by the microbial strain in the rhizosphere bind to the unavailable form of $\mathrm{Fe}^{3+}$ and make iron available to the plants, leading thereby to an increase in plant growth. In general, the reduction of plant growth in $\mathrm{Ni}$ contaminated soil is often associated with iron deficiency and reduced uptake of some other essential element [62]. In the present study, siderophore produced by PGPB might have helped plant root proliferation and enhanced the uptake of soil minerals such as iron.

IAA production was observed for all strains (Table 3). Strain SRA2 produced the highest amount, $87.7 \mathrm{mg} \mathrm{l}^{-1}$ of IAA, whereas SRP4 produced only $22.0 \mathrm{mg} \mathrm{l}^{-1}$ of IAA. SRA1, SRA10 and SRP12 produced similar amounts of IAA, i.e., 76.7, 72.5, and $74.9 \mathrm{mgl}^{-1}$, respectively. This result is in good agreement with the value shown in Table 2 concerning the efficiency of PGPR on plant growth promotion under Ni stress. For instance, the maximum IAA produced by stain SRA2 inoculation resulted in a correspondingly higher fresh and dry biomass of both $B$. juncea and $B$. oxyrrhina suggesting that there was a significant relationship between the plant growth promoting potential of serpentine strains and their level of IAA production. The results of this study are congruent with those of Rajkumar and Freitas [34] reported that P. jessenii PjM15 promoted the growth of $R$. communis plant under $\mathrm{Ni}, \mathrm{Cu}$ and $\mathrm{Zn}$ stress through production of IAA. Gravel et al. [40] observed a significant relationship between plant growth promoting activity of PGPB and their level of IAA production. In general, the IAA produced by PGPB promotes root growth by directly stimulating plant cell elongation or cell division [63]. A low level of IAA produced by rhizosphere bacteria promotes primary root elongation whereas a high level of IAA stimulates lateral and adventitious root formation but inhibit primary root growth [64]. In addition to IAA production, the phosphate solubilization by PGPB is believed to play an important role in plant-bacterial interactions and plant growth in metal contaminated soils [50]. In the present study, all five strains showed the phosphate-solubilizing ability by utilizing the insoluble tricalcium phosphate in modified Pikovskayas medium (Table 3). The decolorization of bromophenol blue is due to a decrease in $\mathrm{pH}$, which clearly indicates the production of organic and inorganic acids, which is considered to be responsible for phosphate solubilization [65]. The strain SRA10 recorded the maximum solubilization of phosphate followed by SRA1. Earlier studies have demonstrated that the elevated levels of $\mathrm{Ni}$ in soil interfere with uptake of nutrients such as P and lead to plant growth retardation [66]. This deficiency can be compensated by the phosphate-solubilizing ability of PGPB strains [50,67]. 
PGPB inoculation has been reported to have a positive influence on various plant growth parameters, including root and shoot length, seedling vigour, fresh and dry biomass. ACC deaminase and siderophore-producing bacteria has been reported to prevent the inhibition of root elongation by decreasing the level of growth-limiting ethylene through hydrolytic cleavage (deaminase activity) of the ethylene biosynthesis precursor ACC and inhibiting the activity of ACC synthase $[8,39,42,68]$. In our study, though the strain SRA2 showed moderate ACC deaminase activity ( $55 \mu \mathrm{m}$ $\alpha-K B g^{-1} h^{-1}$ ), it was more efficient in the promotion of plant growth under Ni stress (Table 2 ). The results suggest that the effects of other plant growth promoting substance such as the production of IAA, and solubilization of phosphate should also be considered in addition to just ACC deaminase activity [45]. Further, the absence of any concomitant increase in root length (Table 1 ) relative to the magnitude of ACC deaminase activity in this study also confirms the previous report that an optimum of $20 \mathrm{nmol} \alpha-\mathrm{KB} \mathrm{mg}^{-1} \mathrm{~h}^{-1}$ protein is sufficient for bacterial strains to have plant growth promoting properties [69]. Nonetheless, growth promotion of the $B$. juncea and $B$. oxyrrhina plants under Ni stress conditions confirmed the beneficial effects of these serpentine bacterial strains on plant growth.

\subsection{Effects of PGPB on the mobility of $\mathrm{Ni}$}

In addition to plant growth promoting potential, certain metal resistant PGPB have been shown to possess several traits that can alter heavy metal mobility and availability to the plant, through acidification, or by producing iron chelators, siderophores, organic acids and/or mobilizing the metal phosphates [11,50,70]. Hence, in the present study the efficiency of PGPB strains in enhancing $\mathrm{Ni}$ solubilization in soils was analyzed. Compared with control treatment, inoculation of PGPB stains SRA1, SRA10 and SRP12 for 5 days, significantly increased the concentrations of bioavailable Ni by $51 \%, 50 \%$ and $44 \%(p<0.05)$, respectively (Fig. 2 ). However, strain SRA2 significantly decreased the amount of Ni extracted from soil. The increase in the concentration of bioavailable Ni caused by SRA1 and SRA10 may be attributed to the maximum production of siderophores and solubilization of phosphate [11,34]. Siderophore production can also be stimulated by the presence of heavy metals [71] and because most siderophores show affinity to bivalent metal ions [72], they possibly affect bioavailability as well. This result is in good agreement with the value shown in Fig. 1 concerning the

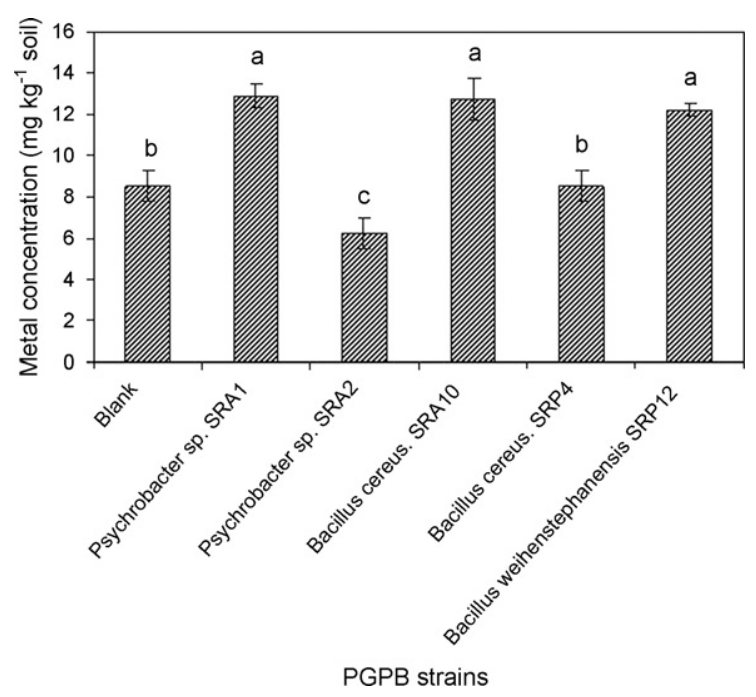

Fig. 2. Effects of inoculation with PGPB strains on the mobilization of Ni in soil. Data of columns indexed by the same letter are not significantly different between PGPB treatments according to Fisher's protected LSD test $(p<0.05)$. influence of PGPB on Ni accumulation in B. juncea and B. oxyrrhina. The higher water soluble Ni induced by SRA1 and SRA2 inoculation resulted in a correspondingly higher $\mathrm{Ni}$ accumulation in both the shoots and roots of $B$. juncea suggesting that the bioavailability of Ni was increased by through bacterial metabolic activities or their interactions with the plants. Similar observations have also reported by Abou-Shanab et al. [11], who observed the inoculation of Ni-resistant bacteria to surface-sterilized seeds of Allysum murale grown in non-sterile soil increased Ni uptake into the shoot by $17 \%$ (Sphingomonas macrogoltabidus), $24 \%$ (Microbacterium liquefaciens), and 32.4\% (M. arabinogalactanolyticum), compared with un-inoculated controls. However, there was some opposite viewpoint that the presence of PGPB on the roots of plants decreased the uptake of metals by the plants. For example, Dell'Amico et al. [43] found that cadmium-resistant rhizobacteria did not influence the specific accumulation of cadmium in the root and shoot systems, but all increased the plant biomass and consequently the total cadmium accumulation of the B. napus. Hence, extensive research is necessary to examine the influence of PGPB inoculation on heavy metal speciation changes in the rhizosphere soil and to determine whether such changes could have altered the accumulation and distribution of heavy metals in various hyperaccumulating plants.

\section{Conclusions}

The results obtained here indicate that inoculation of metal resistant serpentine strains seemed to be very effective in protecting plants from growth inhibition caused by Ni. Enhancing metal accumulation in high yielding crop plants without diminishing their yield is fundamental to successful phytoremediation [3]. In the present study, though the strains SRA1 and SRA10 increased the Ni concentration in the root and shoot tissues of $B$. juncea and $B$. oxyrrhina, these strains failed to promote the plant growth against the toxic effects of $\mathrm{Ni}$ in soils. However, compared with control treatments, inoculation of efficient plant growth promoting strain SRA2 did not influence the quantity of accumulation of $\mathrm{Ni}$ in plant tissues, but achieved a much larger aboveground biomass harvest, thus resulting in a much higher metal removal. The intrinsic abilities of metal mobilization and the ability to reduce the toxicity of nickel of the tested PGPB strains could be of practical importance in augmenting the growth and phytoextraction in nickel polluted soils. As the technology of metal 'phytomining' matures and is commercially developed, even small increases in the total metal uptake and plant growth can have very significant impacts on profitability. Thus, suitable modification of the roots/rhizosphere system of heavy metal phytoaccumulators with beneficial microflora could promote metal bioavailability and phytoextraction. Future studies will examine the co-inoculation effects of Ni mobilizing (Psychrobacter sp. SRA1 and B. cereus SRA10) and PGPB (Psychrobacter sp. SRA2) under field conditions and examine their impact on other metal hyperaccumulating as well as non-hyperaccumulating plants.

\section{References}

[1] S.P. McGrath, A.M. Chaudri, K.E. Giller, Long-term effects of metals in sewage sludge on soils, microorganisms and plants, J. Ind. Microbiol. 14 (2) (1995) 94-104.

[2] M.J. Mclaughlin, D.R. Parker, J.M. Clarke, Metals and micronutrients-food safety issues, Field Crops Res. 60 (1999) 143-163.

[3] M.J. Blaylock, D.E. Salt, S. Dushenkov, O. Zakharova, C. Gussman, Y. Kapulnik, B.D. Ensley, I. Raskin, Enhanced accumulation of Pb in Indian mustard by soil-applied chelating agents, Environ. Sci. Technol. 31 (1997) 860-865.

[4] M.F. Quartacci, A. Argilla, A.J.M. Baker, F. Navari-Izzo, Phytoextraction of metals from a multiply contaminated soil by Indian mustard, Chemosphere 63 (2006) 918-925.

[5] A.J.M. Baker, R.R. Brooks, Terrestrial higher plants which hyperaccumulate metallic elements-a review of their distribution, ecology and phytochemistry, Biorecovery 1 (1989) 81-126. 
[6] Z.G. Shen, Y.L. Liu, Progress in the study on the plants that hyperaccumulate heavy metal, Plant Physiol. Comp. 34 (1998) 133-139.

[7] L. Guo, J. Andrews, R. Riding, P. Dennis, Q. Dresser, Possible microbial effects on stable carbon isotopes in hot-spring travertines, J. Sediment. Res. 66 (1996) 468-473.

[8] A.A. Belimov, N. Hontzeas, V.I. Safronova, S.V. Demchinskaya, G. Piluzza, S. Bullitta, B.R. Glick, Cadmium-tolerant plant growth-promoting bacteria associated with the roots of Indian mustard (Brassica juncea LCzern.), Soil Biol. Biochem. 37 (2005) 241-250.

[9] R.C. Black, D.M. Choate, S. Bardhan, N. Revis, L.L. Barton, T.G. Zocco, Chemical transformation of toxic metals by a Pseudomonas strain from a toxic waste site, Environ. Toxicol. Chem. 12 (1993) 1365-1376.

[10] M.P. De-Souza, C.P.A. Huang, N. Chee, N. Terry, Rhizosphere bacteria enhance that accumulation of selenium and mercury in wetland plants, Planta 209 (1999) 259-263.

[11] R.A. Abou-Shanab, J.S. Angle, T.A. Delorme, R.L. Chaney, P. van Berkum, H. Moawad, K. Ghanem, H.A. Ghozlan, Rhizobacterial effects on nickel extraction from soil and uptake by Alyssum murale, New Phytol. 158 (2003) 219-224.

[12] R. Idris, R. Trifonova, M. Puschenreiter, W.W.Wenzel, A. Sessitsch, Bacterial communities associated with flowering plants of the Ni hyperaccumulator Thaspi goesingense, Appl. Environ. Microbiol. 70 (2004) 2667-2677.

[13] S.N. Whiting, M.P. De-Souza, N. Terry, Rhizosphere bacteria mobilize $\mathrm{Zn}$ for hyperaccumulation by Thlaspi caerulescens, Environ. Sci. Technol. 15 (2001) 3144-3150.

[14] R.A. Abou-Shanab, P. van Berkum, J.S. Angle, Heavy metal resistance and genotypic analysis of metal resistance genes in gram-positive and gram-negative bacteria present in Ni-rich serpentine soil and in the rhizosphere of Alyssum murale, Chemosphere 68 (2) (2007) 360-367.

[15] H.G. Schlegel, J.P. Cosson, A.M. Baker, Nickel hyperaccumulating plants provide a niche for nickel-resistant bacteria, Bot. Acta 104 (1991) 18-25.

[16] A. Mengoni, R. Barzanti, C. Gonneli, R. Gabbrielli, M. Bazzicalupo, Characterization of nickel-resistant bacteria isolated from serpentine soil, Environ. Microbiol. 3 (2001) 691-708.

[17] R.I. Abou-Shanab, T.A. Delorme, J.S. Angle, R.L. Chaney, K. Ghanem, H. Moawad, H.A. Ghozlan, Phenotypic characterization of microbes in the rhizosphere of Alyssum murale, Int. J. Phytorem. 5 (2003) 367-380.

[18] H. Freitas, M.N.V. Prasad, J. Pratas, Analysis of serpentinophytes from north-east of Portugal for trace metal accumulation relevance to the management of mine environment, Chemosphere 54 (2004) 1625-1642.

[19] M. Rajkumar, R. Nagendran, K.J. Lee, W.H. Lee, Characterization of a novel $\mathrm{Cr}^{6+}$ reducing Pseudomonas sp. with plant growth-promoting potential, Curr. Microbiol. 50 (2005) 266-271.

[20] M. Dworkin, J. Foster, Experiments with some microorganisms which utilize ethane and hydrogen, J. Bacteriol. 75 (1958) 592-601.

[21] ISTA, International rules for seed testing, Proc. Int. Seed Test Assoc. 31 (1966) $1-152$.

[22] A.A. Abdul-Baki, J.D. Anderson, Vigour determination in soya bean seed by multiple criteria, Crop Sci. 13 (1973) 630-633.

[23] J. Sambrook, E.F. Fritsch, T. Maniatis, Molecular Cloning, A Laboratory Manual, 2nd ed., Cold Spring Harbor Laboratory Press, Cold Spring Harbor, 1989.

[24] J. Dunbar, S. Takala, S.M. Barns, J.A. Davis, C.R. Kuske, Levels of bacterial community diversity in four arid soils compared by cultivation and 16S rRNA gene cloning, Appl. Environ. Microb. 65 (1999) 1662-1669.

[25] R. Branco, A.P. Chung, A. Verr'ssimo, P.V. Morais, Impact of chromiumcontaminated wastewaters on the microbial community of a river, FEMS Microbiol. Ecol. 54 (2005) 35-46.

[26] S.F. Altschul, T.L. Madden, A.A. Schaffer, J. Zhang, Z. Zhang, W. Miller, D.J. Lipman, Gapped BLAST and PSIBLAST: a new generation of protein database search programs, Nucleic Acids Res. 25 (1997) 3389-3402.

[27] M. Honma, T. Shimomura, Metabolism of 1-aminocyclopropane-1-carboxylic acid, Agric. Biol. Chem. 42 (1978) 1825-1831.

[28] J.M. Bric, R.M. Bostock, S.E. Silversone, Rapid in situ assay for indole acetic acid production by bacteria immobilization on a nitrocellulose membrane, Appl. Environ. Microb. 57 (1991) 535-538.

[29] B. Schwyn, J.B. Neilands, Universal chemical assay for the detection and determination of siderophores, Anal. Biochem. 160 (1987) 47-56.

[30] E. Arnow, Colorimetric determination of the components of 3,4dihydroxyphenylalanine-tyrosine mixtures, J. Biol. Chem. 118 (1937) 531-537.

31] C.L. Atkin, J.B. Neilands, H.J. Phaff, Rhodotorulic acid from species of Leucosporid ium, Rhodosporidium, Rhodotorula, Sporidiobolus, and Sporobolomyces, and a new alanine-containing ferrichrome from Cryptococcus melibiosum, J. Bacteriol. 103 (1970) 722-733.

[32] W.V.B. Sundara-Rao, M.K. Sinha, Phosphate dissolving microorganisms in the soil and rhizosphere, Indian J. Agric. Sci. 33 (1963) 272-278.

[33] C.H. Fiske, Y. Subbarow, A colorimetric determination of phosphorus, J. Biol. Chem. 66 (1925) 375-400.

[34] M. Rajkumar, H. Freitas, Influence of metal resistant-plant growth-promoting bacteria on the growth of Ricinus communis in soil contaminated with heavy metals, Chemosphere 71 (2008) 834-842.

[35] Z. Piotrowska-Seget, M. Cycon, J. Kozdrój, Metal-tolerant bacteria occurring in heavily polluted soil and mine spoil, Appl. Soil Ecol. 28 (2005) 237246

[36] A. Pal, S. Dutta, P.K. Mukherjee, A.K. Paul, Occurrence of heavy metal-resistance in microflora from serpentine soil of Andaman, J. Basic Microbiol. 45 (2005) 207-218.
[37] A. Pal, G. Wauters, A.K. Paul, Nickel tolerance and accumulation by bacteria from rhizosphere of nickel hyperaccumulators in serpentine soil ecosystem of Andaman, India, Plant Soil 293 (2007) 37-48.

[38] C.B. Jacobson, JJ. Pasterna, B.R. Glick, Partial purification and characterization of 1-aminocyclopropane-1-carboxylate deaminase from the plant growth promoting rhizobacterium Pseudomonas putida GR12-2, Can. J. Microbiol. 40 (1994) 1019-1025.

[39] M. Madhaiyan, S. Poonguzhali, J.H. Ryu, T.M. Sa, Regulation of ethylene levels in canola (Brassica campestris) by 1-aminocyclopropane-1-carboxylate deaminase-containing Methylobacterium fujisawaense, Planta 224 (2006) 268-278.

[40] V. Gravel, H. Antoun, R.J. Tweddell, Growth stimulation and fruit yield improvement of greenhouse tomato plants by inoculation with Pseudomonas putida or Trichoderma atroviride: possible role of indole acetic acid (IAA), Soil Biol. Biochem. 39 (2007) 1968-1977.

[41] B. Shaharoona, G.M. Jamro, Z.A. Zahir, M. Arshad, K.S. Memon, Effectiveness of various Pseudomonas spp. and Burkholderia caryophylli containing ACCdeaminase for improving growth and yield of wheat (Triticum aestivum L.), J. Microbiol. Biotechnol. 17 (8) (2007) 1300-1307.

[42] C. Contesto, G. Desbrosses, C. Lefoulon, G. Béna, F. Borel, M. Galland, L. Gamet F. Varoquaux, B. Touraine, Effects of rhizobacterial ACC deaminase activity on Arabidopsis indicate that ethylene mediates local root responses to plant growth-promoting rhizobacteria, Plant Sci. PSL-7826 (2008) 12.

[43] E. Dell'Amico, L. Cavalca, V. Andreoni, Improvement of Brassica napus growth under cadmium stress by cadmium-resistant rhizobacteria, Soil Biol. Biochem. 40 (2008) 74-84

[44] C.Y. Jiang, X.F. Sheng, M. Qian, Q.Y. Wang, Isolation and characterization of a heavy metal-resistant Burkholderia sp. From heavy metal-contaminated paddy field soil and its potential in promoting plant growth and heavy metal accumulation in metal-polluted soil, Chemosphere 72 (2008) 157-164.

[45] Y. Ma, M. Rajkumar, H. Freitas, Inoculation of plant growth promoting bacterium Achromobacter xylosoxidans strain Ax10 for the improvement of copper phytoextraction by Brassica juncea, J. Environ. Manage. 90 (2009) 831837.

[46] M. Rajkumar, H. Freitas, Effects of inoculation of plant-growth promoting bacteria on Ni uptake by Indian mustard, Biores. Technol. 99 (2008) 34913498.

[47] C. Mattioni, R. Gabbrielli, J. Van Gronsveld, H. Clijsters, Nickel and cadmium toxicity and enzymatic activity in Ni-tolerant and non-tolerant populations of Silene italica Pers, J. Plant Physiol. 150 (1997) 173-177.

[48] M.M. Alam, S. Hayat, B. Ali, A. Ahmad, Effect of 28-homobrassinolide treatment on nickel toxicity in Brassica juncea, Photosynthetica 45 (2007) 139-142.

[49] A.K. Sen, M. Bhattacharyya, Studies of uptake and toxic effects of Ni (II) on Salvinia natans, Water Air Soil Pollut. 78 (2004) 141-152.

[50] S. Zaidi, S. Usmani, B.R. Singh, J. Musarrat, Significance of Bacillus subtilis strain SJ-101 as a bioinoculant for concurrent plant growth promotion and nickel accumulation in Brassica juncea, Chemosphere 64 (2006) 991-997.

[51] G.I. Burd, D.G. Dixon, B.R. Glick, A plant growth-promoting bacterium that decreases nickel toxicity in seedlings, Appl. Environ. Microbiol. 64 (3) (1998) 3663-3668.

[52] A.K. Gupta, S. Sinha, Chemical fractionation and heavy metals accumulation in the plants of Sesamum indicum (L.) var. T55 grown on soil amended with tannery sludge: selection of single extractants, Chemosphere 64 (2006) 161-173.

[53] R.A.I. Abou-Shanab, J.S. Angle, R.L. Chaney, Bacterial inoculants affecting nicke uptake by Alyssum murale from low, moderate and high Ni soils, Soil Biol. Biochem. 38 (2006) 2882-2889.

[54] X.F. Sheng, J.J. Xia, Improvement of rape (Brassica napus) plant growth and cadmium uptake by cadmium-resistant bacteria, Chemosphere 64 (2006) 1036-1042.

[55] M. Madhaiyan, S. Poonguzhali, T.M. Sa, Metal tolerating methylotrophic bacteria reduces nickel and cadmium toxicity and promotes plant growth of tomato (Lycopersicon esculentum L.), Chemosphere 69 (2007) 220-228.

[56] P.B.A.N. Kumar, V. Dushenkov, H. Motto, I. Raskin, Phytoextraction: the use of plants to remove heavy metals, Environ. Sci. Technol. 29 (1995) 1232 1238

[57] G.I. Burd, D.G. Dixon, B.R. Glick, Plant growth-promoting bacteria that decrease heavy metal toxicity in plants, Can. J. Microbiol. 46 (2000) 237-245.

[58] A.A. Belimov, V.I. Safronova, T.A. Sergeyeva, T.N. Egorova, V.A. Matveyeva, V.E Tsyganov, Characterization of plant growth-promoting rhizobacteria isolated from polluted soils and containing 1-aminocyclopropane-1-carboxylate deaminase, Can. J. Microbiol. 47 (2001) 642-652.

[59] X.F. Sheng, L.Y. He, Q.Y. Wang, H.S. Ye, C.Y. Jiang, Effects of inoculation of biosurfactant-producing Bacillus sp. J119 on plant growth and cadmium uptake in a cadmium-amended soil, J. Hazard. Mater. 155 (2008) 17-22.

[60] K.V. Kumar, N. Singh, H.M. Behl, S. Srivastava, Influence of plant growth promoting bacteria and its mutant on heavy metal toxicity in Brassica juncea grown in fly ash amended soil, Chemosphere 72 (2008) 678-683.

[61] V.I. Safronova, V.V. Stepanok, G.L. Engqvist, Y.V. Alekseyev, A.A. Belimov, Rootassociated bacteria containing 1-aminocyclopropane-1-carboxylate deaminase improve growth and nutrient uptake by pea genotypes cultivated in cadmium supplemented soil, Biol. Fertil. Soils 42 (2006) 267-272.

[62] D. Mishra, M. Kar, Nickel in plant growth and metabolism, Bot. Rev. 40 (1974) 395-452

[63] B.R. Glick, D.M. Penrose, J. Li, A model for the lowering of plant ethylene concentrations by plant growth promoting bacteria, J. Theor. Biol. 190 (1998) $63-68$. 
[64] H. Xie, JJ. Pasternak, B.R. Glick, Isolation and characterization of mutants of the plant growth-promoting rhizobacterium Pseudomonas putida GR12-2 that overproduce indoleacetic acid, Curr. Microbiol. 32 (1996) 67-71.

[65] R.P. Pareek, A.C. Gaur, Release of phosphate from tricalcium phosphate by organic acids, Curr. Sci. 42 (1973) 278-279.

[66] R.L. Halstead, B.J. Finn, A.J. MacLean, Extractibility of nickel added to soils and its concentration in plants, Can. J. Soil Sci. 49 (1969) 335-342.

[67] A. Gupta, J.M. Meyer, R. Goel, Development of heavy metal resistant mutants of phosphate solubilizing Pseudomonas sp. NBRI4014 and their characterization, Curr. Microbiol. 45 (2002) 323-327.

[68] J.C. Stearns, S. Shah, B.M. Greenberg, D.G. Dixon, B.R. Glick, Tolerance of transgenic canola expressing 1-aminocyclopropane-1-carboxylic acid deaminase to growth inhibition by nickel, Plant Physiol. Biochem. 43 (2005) 701-708.
[69] D.M. Penrose, B.R. Glick, Methods for isolating and characterizing of ACC deaminase-containing plant growth promoting rhizobacteria, Physiol. Plant 118 (2003) 10-15.

[70] S.C. Wu, K.C. Cheung, Y.M. Luo, M.H. Wong, Effects of inoculation of plant growth-promoting rhizobacteria on metal uptake by Brassica juncea, Environ. Pollut. 140 (2006) 124-135.

[71] D. van der Lelie, P. Corbisier, L. Diels, A. Gilis, C. Lodewyckx, M. Mergeay, S. Taghavi, N. Spelmans, J. Vangronsveld, The role of bacteria in the phytoremediation of heavy metals, in: N. Terry, G. Banuelos (Eds.), Phytoremediation of Contaminated Soil and Water, Lewis Publishers, London, United Kingdom, 1999, pp. 265-281.

[72] J.B. Neilands, Microbial iron compounds, Annu. Rev. Biochem. 50 (1981) 715-731. 